\title{
The Role of Serum Laboratory Biomarkers for Complicated and Uncomplicated Appendicitis in Adolescents
}

\author{
Serkan Sengul, Yilmaz Guler, Hasan Calis and Zulfikar Karabulut \\ Department of General Surgery, Alanya Alaaddin Keykubat University, Alanya, Antalya, Turkey
}

\begin{abstract}
Objective: To investigate if serum biomarkers could differentiate complicated and uncomplicated appendicitis in adolescents. Study Design: An cross sectional study.

Place and Duration of Study: Department of General Surgery, Faculty of Medicine, Alanya Alaaddin Keykubat University, Alanya, Turkey, between January 2016 and December 2018.

Methodology: Patients operated for acute appendicitis, aged between 10 and 19 years, were retrospectively evaluated. Patients were divided according to the negative appendectomy (group 1), uncomplicated appendicitis (group 2A) and complicated appendicitis (group 2B). White blood cell count (WBC), neutrophil count (NEU), lymphocyte count (LC), neutrophil/lymphocyte ratio (NLR), mean platelet volume (MPV), red cell distributions width (RDW), C-reactive protein (CRP), and length of hospital stay (LoHS) were analysed by ROC curve, one-way and Mann-Whitney U-tests.

Results: There were 277 adolescents (group $1=30$, group $2 A=205$ and group $2 B=42$ ). There were statistically significant differences between the groups in WBC, NEU, LYM, NLR, CRP, LoHS. The cut-off values of NLR, WBC, and NEU were $4.1,10.6 \times 10^{9} / \mathrm{L}$, and $8.17 \times 10^{9} / \mathrm{L}$, respectively for uncomplicated appendicitis, and $7.32,11.5 \times 10^{9} / \mathrm{L}$, and $10.3 \times 10^{9} / \mathrm{L}$, respectively for complicated appendicitis. The cut off value of CRP was $1.3 \mathrm{mg} / \mathrm{dl}$ for complicated appendicitis.

Conclusions: Elevated WBC, NEU, CRP and NLR may be considered useful biomarkers in assisting physical examination and other diagnostic methods in distinguishing severity of acute appendicitis.
\end{abstract}

Key Words: Adolescent, Appendicitis, Neutrophil-to-lymphocyte ratio, C-reactive protein, Length of hospital stay.

How to cite this article: Sengul S, Guler Y, Calis H, Karabulut Z. The Role of Serum Laboratory Biomarkers for Complicated and Uncomplicated Appendicitis in Adolescents. J Coll Physicians Surg Pak 2020; 30(04):420-424. DOI: https://doi.org/10.29271/jcpsp.2020.04.420.

\section{INTRODUCTION}

Appendicitis is seen in $1-8 \%$ of paediatric population who are admitted to the emergency department for abdominal pain. Appendicitis in Childhood is most common in the adolescence period. ${ }^{1}$ Clinical classification of appendicitis has been reported in simple and complicated form in the literature. ${ }^{2}$ Differential diagnosis is critical because non-surgical management has become the preferred treatment option for treatment of simple appendicitis. $^{3}$ Complicated appendicitis is associated with high morbidity, mortality, and costs in the postoperative period. ${ }^{2}$ Differential diagnosis is usually based on medical anamnesis, physical examination, blood tests and imaging methods. ${ }^{4}$ Radiologic methods such as abdominal ultrasound (USG), computed tomography $(\mathrm{CT})$, and magnetic resonance imaging (MRI) in selected cases are useful in diagnosis of simple and complicated appendicitis. ${ }^{5}$ However, the use of these methods can be limited due to the need for experienced radiologists and equipment, and higher cost.

Correspondence to: Dr. Serkan Sengul, Department of General Surgery, Alanya Alaaddin Keykubat University, Alanya, Antalya, Turkey

E-mail: serkan.sengul@alanya.edu.tr

Received: May 28, 2019; Revised: September 18, 2019;

Accepted: September 18, 2019

DOI: https://doi.org/10.29271/jcpsp.2020.04.420
Despite all diagnostic methods, negative appendectomy rates have been reported up to $30 \%$ in the literature. ${ }^{6}$ Therefore, clinicians have been investigating simpler methods for definitive diagnosis.

In recent years, authors have focused on diagnostic biomarkers for the discrimination of simple and complicated appendicitis. ${ }^{7,8}$ These include white blood cell (WBC), C-reactive protein (CRP), neutrophil-to-lymphocyte ratio (NLR), mean platelet volume (MPV), red cell distribution width (RDW), and platelet distribution width (PDW). There are conflicting results in the literature regarding the use of these biomarkers for the diagnostic discrimination of appendicitis. ${ }^{3,9,10}$

In this study, the aim was to investigate if serum biomarkers could predict simple and complicated appendicitis in adolescent patients.

\section{METHODOLOGY}

Patients aged 10 to 19 years, who were operated (open or laparoscopic surgery) for acute appendicitis between January 2016 and December 2018, retrospectively were evaluated. Patients' demographics, laboratory tests including white blood cell count (WBC), neutrophil count (NEU), lymphocyte count (LC), neutrophil/lymphocyte ratio (NLR), mean platelet volume (MPV), red cell distribution width (RDW), C-reactive protein (CRP), pathology results, and length of hospital stay (LoHS) were recorded. Diabetes mellitus, heart and liver disease, hematologic disease, morbid obesity and use of medications, which can affect serum biomarkers count, were excluded. 
Table I: The comparison of demographics and laboratory values between the group.

\begin{tabular}{|c|c|c|c|c|}
\hline & $\begin{array}{c}\text { Group } 1 \\
\text { (negative appendicectomy) }\end{array}$ & $\begin{array}{c}\text { Group 2A } \\
\text { (uncomplicated appendicitis) }\end{array}$ & $\begin{array}{c}\text { Group 2B } \\
\text { (complicated appendicitis) }\end{array}$ & $\mathbf{p}$ \\
\hline Number of patients & 30 & 205 & 42 & \\
\hline Mean age (years) & 16.1 & 14.7 & 14.6 & \\
\hline Male & 13 & 145 & 27 & \\
\hline Female & 17 & 60 & 15 & \\
\hline WBC $\left(\times 10^{9} / \mathrm{L}\right)$ & $10.1 \pm 3.3$ & $13.0 \pm 4.1$ & $16.1 \pm 4.1$ & 0.00 \\
\hline $\operatorname{NEU}\left(\times 10^{9} / \mathrm{L}\right)$ & $7.3 \pm 3.3$ & $10 \pm 3.9$ & $15.3 \pm 3.1$ & 0.00 \\
\hline LYM (x10²/L) & $2.5 \pm 3.7$ & $1.8 \pm 0.7$ & $1.3 \pm 0.5$ & 0.00 \\
\hline NLR & $4.2 \pm 2.5$ & $6.2 \pm 3.4$ & $13.8 \pm 6.7$ & 0.00 \\
\hline MPV (fL) & $8.2 \pm 0.7$ & $8.5 \pm 0.8$ & $8.6 \pm 0.8$ & 0.24 \\
\hline PDW (fL) & $14.1 \pm 1.9$ & $14.6 \pm 2.6$ & $14.6 \pm 2.5$ & 0.58 \\
\hline RDW (\%) & $15.4 \pm 1.3$ & $15.4 \pm 1.4$ & $14.8 \pm 1.1$ & 0.05 \\
\hline CRP (mg/dL) & $1 \pm 1.8$ & $1.8 \pm 3.5$ & $7.8 \pm 6.2$ & 0.00 \\
\hline LoHS (days) & $1.6 \pm 0.9$ & $2.2 \pm 1.3$ & $4.3 \pm 2.1$ & 0.00 \\
\hline
\end{tabular}

Table II: Receiver operating characteristic curve (ROC) for the significant parameters in diagnosis of acute appendicitis.

\begin{tabular}{|c|c|c|c|c|c|c|c|}
\hline & \multirow{2}{*}{ AUROC } & \multicolumn{2}{|c|}{$\% 95 \mathrm{Cl}$} & \multirow{2}{*}{ Cut-off } & \multirow{2}{*}{ Sensitivite (\%) } & \multirow{2}{*}{ Spesifite (\%) } & \multirow{2}{*}{$\mathbf{p}$} \\
\hline & & Lower limit & Upper limit & & & & \\
\hline NLR & 0,670 & 0.568 & 0.771 & $\geq 4.1$ & 67.3 & 63.3 & 0.03 \\
\hline WBC $\left(\times 10^{9} / L\right)$ & 0.708 & 0.613 & 0.803 & $\geq 10.6$ & 72.2 & 60 & 0.00 \\
\hline $\operatorname{NEU}\left(x 10^{9} / \mathrm{L}\right)$ & 0.699 & 0.601 & 0.797 & $\geq 8.17$ & 70.7 & 73.3 & 0.00 \\
\hline
\end{tabular}

Table III: Receiver operating characteristic curve (ROC) for the significant parameters in diagnosis of complicated appendicitis.

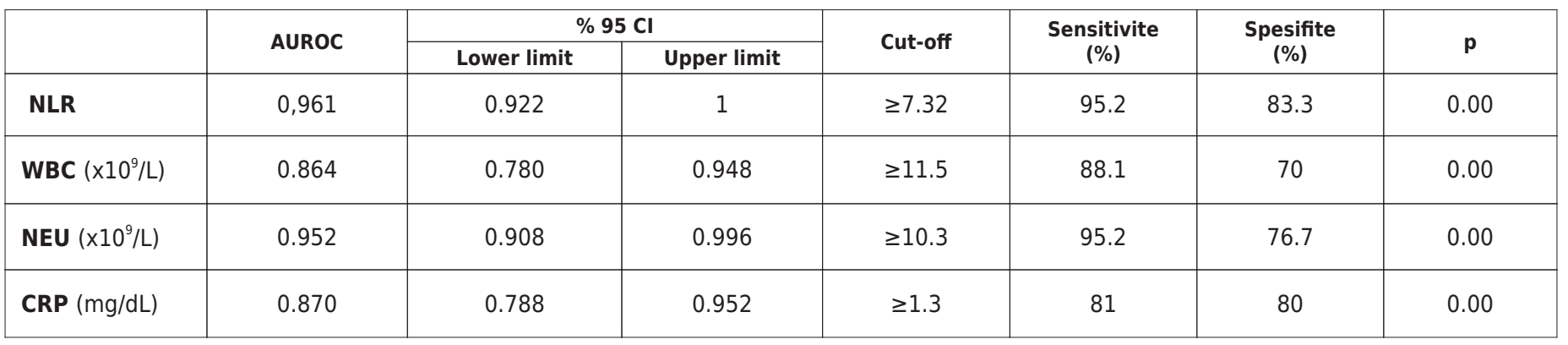

Patients were divided into 2 groups in terms of histopatho-logical evaluation. Group 1 included negative appendectomy (normal appendix) and group 2 included acute appendicitis. Group 2 was divided into 2 subgroups. Group 2A included uncomplicated appendicitis and Group 2B included complicated (perforated) appendicitis. Length of hospital stay was recorded. This study was approved by local Ethical Committee of the Institution.

The statistical analysis was performed using SPSS (version 20.0 for Mac, Armonk, NY, US) software. The comparisons among groups regarding quantitative data were done by using one-way test. The cut-off value of laboratory parameters were calculated using receiver operating characteristic (ROC) curve analysis. The confidence interval $(\mathrm{Cl})$ was set at $95 \%$ and $p$ value was considered significant at a level of $<0.05$. Appropriate cut-off values were identified, and sensitivity, specificity were calculated for parameters with an area under the curve (AUC) of above 0.600 . The Mann-Whitney U-test was performed to detect if there was a difference in LoHS between complicated and uncomplicated appendicitis. 


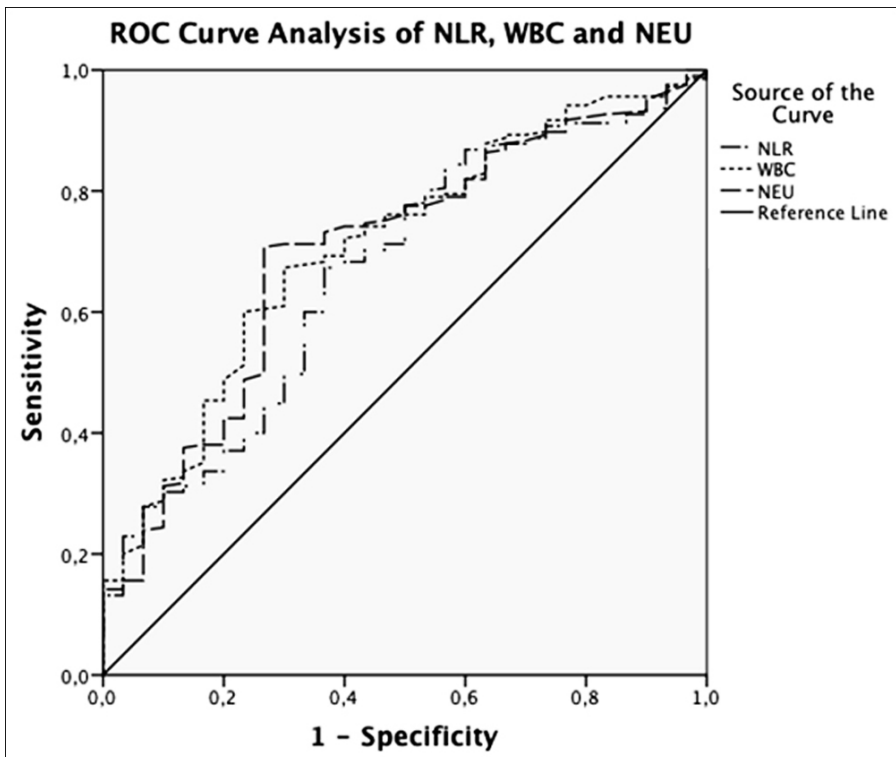

Figure I. Receiver operating characteristic (ROC) curve analyses of significant parameters (NLR, WBC and NEU) for diagnosis of uncompli-cated appendicitis.

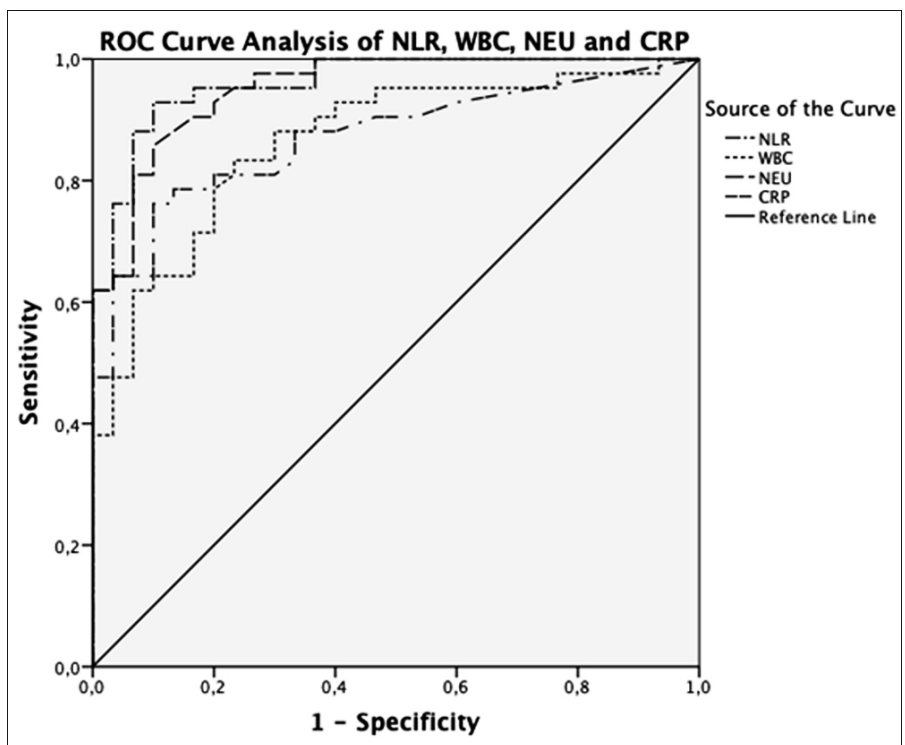

Figure 2. Receiver operating characteristic (ROC) curve analyses of significant parameters (NLR, WBC, NEU and CRP) for diagnosis of complicated appendicitis.

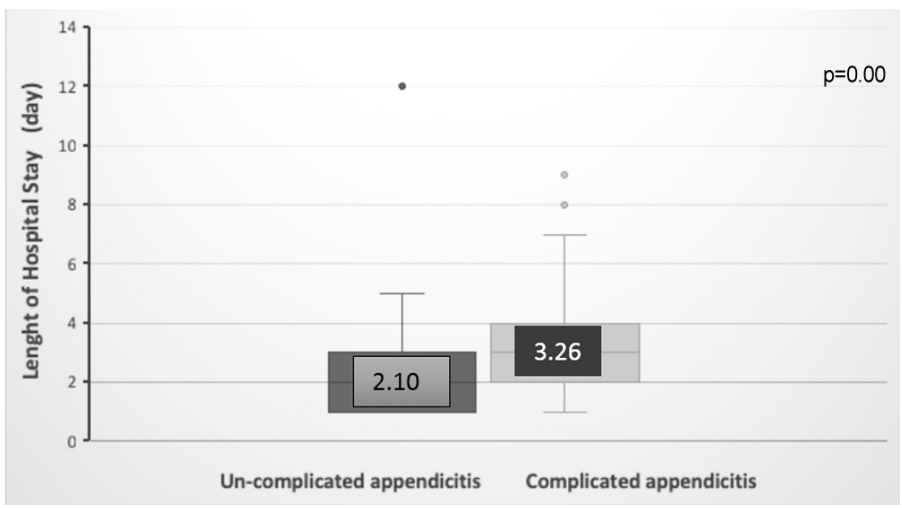

Figure 3. Difference in the mean lenght of hospital stay betweeen uncomplicated / complicated appendicitis ( $p=0.00$ Mann- Whitney test).

\section{RESULTS}

A total of 277 patients were included in the current study. Of these, 30 (10.8\%) were in group 1 (negative appendectomy) and $247(89.2 \%)$ were in group 2 (acute appendicitis). There were 205 (82.9\%) patients in group 2A (uncomplicated appendicitis) and 42 (17.1\%) in group 2B (complicated appendicitis). The mean age was $16.1 \pm 2.7$ years in group $1 ; 14.7 \pm 3$ years in group $2 \mathrm{~A}$; and $14.6 \pm 2.8$ years in group $2 \mathrm{~B}$. Table I shows the comparisons of demographic and laboratory values between the groups. There were statistically significant differences between the groups with respect to WBC, NEU, LYM, NLR, CRP, and LoHS. The mean MPV, PDW, and RDW were not statistically significant among the groups.

Diagnostic value of statistically significant parameters was analysed by using ROC analysis. AUROC (Area Under ROC) was above 0.600 for NLR, WBC, and NEU in uncomplicated appendicitis (Figure I). The cut-off value of NLR in differential diagnosis of uncomplicated appendicitis was 4.1 , with sensitivity of $67.3 \%$ and specificity of $63.3 \%$ (AUC: 0.67 ; $95 \% \mathrm{Cl}: 0.568-$ $0.771 ; p=0.03)$. Table II shows the cut-off values and performance characteristics of NLR, WBC and NEU. AUROC above 0.600 was found in NLR, WBC, NEU and CRP in complicated appendicitis (Figure 2). The cut-off value of NLR in differential diagnosis of complicated appendicitis was 7.32, with sensitivity of $95.2 \%$ and specificity of $83.3 \%$ (AUC: $0.961 ; 95 \% \mathrm{Cl}$ : $0.922-1 ; p<0.001)$. Table II shows the cut-off values and performance characteristics of NLR, WBC, NEU, and CRP.

NLR cut-off value of 7.48 predicted overall LoHS between uncomplicated and complicated appendicitis (Table III). While the mean LoHS was $2.10 \pm 1.3$ days for uncomplicated appendicitis, it was $3.26 \pm 1.8$ days for complicated appendicitis $(p<0.001)$.

\section{DISCUSSION}

Acute appendicitis is one of the most common conditions requiring urgent surgery. ${ }^{10}$ Whereas laboratory tests scoring systems, and imaging methods are used to diagnose acute appendicitis: Difficulties and delays in diagnosis in some cases may result in complications. ${ }^{11,12}$ Therefore, researchers have focused on cheap, easy-to-use biomarkers with high diagnostic accuracy. ${ }^{9,10,13}$ Kelly et al. advocated that NLR is a useful predictor of appendicitis severity. ${ }^{7}$ Whereas, some studies have reported the usefulness of MPV and PDW for diagnosing appendicitis. ${ }^{14}$ Some others have pointed that those para-meters were not useful for diagnosing acute appendicitis. ${ }^{8,9}$ In the present study, we revealed no correlation between PDW, MPV, RDW, and acute appendicitis.

WBC is the most frequently used diagnostic laboratory test in acute appendicitis. ${ }^{15}$ Sevinc et al. analysed 3,392 acute appendicitis cases and found a WBC cut-off value of $11.900 / \mathrm{mm}^{3}$ (sensitivity $71.2 \%$; specificity $67.2 \%$ ). ${ }^{8}$ However, Rafiq et al reported a higher sensitivity and a higher specificity at the same WBC cut-off value (sensitivity 87.1\%; specificity $91.7 \%) .{ }^{16}$ Bilici investigated the diagnostic value of WBC cut-off value of $11.000 / \mathrm{mm}^{3}$ (sensitivity $84 \%$; specificity $89 \%$ ) in paediatric cases. $^{13}$ In this study, we found a cut-off value of $10.600 / \mathrm{mm}^{3}$ for WBC (sensitivity $72.2 \%$; specificity $60 \%$ ) in 
adolescents.

Various cut-off values have been reported for acute complicated appendicitis. A study found a cut-off value of $15.800 / \mathrm{mm}^{3}$ (sensitivity $75 \%$; specificity $70 \%$ ). ${ }^{11}$ Jung et al. reported a cutoff value of $10.600 / \mathrm{mm} 3$ (sensitivity $71.2 \%$; specificity $68.2 \%{ }^{17}$ However, Sevinc et al. did not report any cut-off value for WBC in predicting perforation. ${ }^{8}$ The cut-off value was $11.500 / \mathrm{mm}^{3}$ in complicated appendicitis. (sensitivity $88 \%$; specificity $70 \%$ ). Our results were consistent with the literature findings.

Numerous studies have advocated the diagnostic power of NLR at different cut-off values in the diagnosis of AA. ${ }^{18,19}$ Kelly et al reported a NLR cut off value of 5.96 (sensitivity $62 \%$; specificity $79 \%$ ) to differentiate negative and positive appendectomy. ${ }^{7}$ They also found a cut-off value of 6.35 (sensitivity $85 \%$; specificity $48 \%$ ) to discriminate complicated appendicitis. However, they showed a cut-off value of 7.53 (sensitivity $80 \%$, specificity $55 \%$ ) to diagnose perforation under the age of 18 years. Sevinc et al. suggested a cut-off value of 3.0 (sensitivity $81.2 \%$; specificity $53.1 \%$ ) for acute appendicitis and 4.8 (sensitivity $78.4 \%$; specificity $41.7 \%$ ) for perforated appendicitis. $^{8}$ Shimizu et al. reported a cut-off value of 5.0 for NLR in appendicitis and 8.0 for gangrenous appendicitis. ${ }^{18}$ According to the present results, NLR values were significantly different between the uncomplicated, complicated, and negative appendectomy groups $(p<0.001)$. A cut-off value of 4.1 (sensitivity $67.3 \%$; specificity $63.3 \%$ ) was found for NLR to diagnose AA and 7.32 (sensitivity $95.2 \%$; specificity $83.3 \%$ ) to diagnose complicated appendicitis. WBC had the highest sensitivity and specificity in acute appendicitis and NLR in complicated appendicitis.

Neutrophil count is one of the important parameters used for the differential diagnosis between simple appendicitis and complicated appendicitis. Boshnak et al. in a 200-patient prospective study, found a sensitivity of $72.4 \%$ and a specificity of $81.8 \%$ for a cut-off level $9.4 \times 10^{9} / \mathrm{L}$ of neutrophil count for acute appendicitis. ${ }^{10}$ In a paediatric study Bilici et al reported that neutrophil count had a sensitivity of $77 \%$ and a specificity of $91 \%$ for a cut-off level of $>8 \times 10^{9} / \mathrm{L}$ for diagnosing acute appendicitis. ${ }^{13}$ Zani et al. on the other hand, reported that neutrophil count had no diagnostic value for the diagnosis of perforated appendicitis. ${ }^{3}$ In this study, the cut-off value for neutrophil count was $8.17 \times 10^{9} / \mathrm{L}$ (sensitivity $70.7 \%$; specificity $73.3 \%$ ) for acute appendicitis and $10.3 \times 10^{9} / \mathrm{L}$ (sensi-tivity $95.2 \%$, specificity $76.7 \%$ ) for complicated appendicitis.

C-reactive protein is an acute phase reactant and may be used as a diagnostic marker in acute inflammatory conditions. Studies in the literature have reported cut-off levels of CRP ranging between $0.5-1.7 \mathrm{mg} / \mathrm{dL}$ and having sensitivities of $38-91 \%$ and specificities of $26-98 \%{ }^{20}$ The authors could not determine a cut-off level for CRP diagnostic of acute un-complicated appendicitis. However, we found a cut-off value of 1,3 $\mathrm{mg} / \mathrm{dL}$ in acute complicated appendicitis (sensitivity $81 \%$; specificity $80 \%)$.

There is a limited number of studies in the literature investigating the relationship between NLR and length of hospital stay. ${ }^{7,19}$ Those studies have mentioned a predictive role of NLR for LoHS. In agreement with the literature reports, we revealed a mean of one day of hospitalisation time difference between complicated and uncomplicated appen-dicitis.

There are some limitations of this study, viz retrospective nature, low sample size, and inclusion of patients who underwent appendectomy only.

\section{CONCLUSION}

Considering the adolescent age group, WBC, NEU, and NLR appear as useful serum biomarkers for diagnosing acute appendicitis. As for the distinction between uncomplicated and complicated appendicitis, WBC, NEU, CRP, and NLR may be of use. A NLR cut-off level >7,3 may be helpful to make surgeons consider surgical treatment instead of antibiotic-based conservative management to prevent delays. MPV, RDW, and PDW, however, were not significantly helpful for that indi-cation. Nevertheless, large-scale prospective randomised studies are needed to implement these parameters into routine practice.

\section{CONFLICT OF INTEREST:}

Authors declared no conflict of interest.

\section{AUTHORS' CONTRIBUTION:}

SS: Planned and designed the study, co-wrote the manuscript.

YG: Collected and analysed data, co-wrote the manuscript.

$\mathrm{CH}$ : Performed the statistical analysis, Collected and analysed data.

KZ: Revised the manuscript critically.

All authors approved the final version of the article for submission.

\section{REFERENCES}

1. Dahn CM, Milne WK. Hot off the press does this adolescent female have appendicitis can the pediatric appendicitis score help. Acad Emerg Med 2017; 24:130-2.

2. Şahbaz NA, Bat O, Kaya B, Ulukent SC, Illkgül Ö, Özgün MY, et al. The clinical value of leucocyte count and neutrophil percentage in diagnosing uncomplicated (simple) appendicitis and predicting complicated appendicitis. Ulus Travma Acil Cerrahi Derg 2014; 20:423-6.

3. Zani A, Teague WJ, Clarke SA, Haddad MJ, Khurana S, Tsang T, et al. Can common serum biomarkers predict complicated appendicitis in children. Pediatr Surg Int 2017; 33:799-805.

4. Atema JJ, van Rossem CC, Leeuwenburgh MM, Stoker J, Boermeester MA. Scoring system to distinguish uncomplicated from complicated acute appendicitis. Br J Surg 2015; 102:979-90.

5. Xiong B, Zhong B, Li Z, Zhou F, Hu R, Feng Z, et al. Diagnostic accuracy of noncontrast ct in detecting acute appendicitis a meta-analysis of prospective studies. Am Surg 2015; 81:626-9.

6. Ferris M, Quan S, Kaplan BS, Molodecky N, Ball CG, Chernoff $\mathrm{GW}$, et al. The global incidence of appendicitis a systematic review of population-based studies. Ann Surg 2017; 266: 237-41.

7. Kelly ME, Khan A, Riaz M, Bolger JC, Bennani F, Khan W, et al. The utility of neutrophil-to-lymphocyte ratio as a severity predictor of acute appendicitis length of hospital stay and post- 
operative complication rates. Dig Surg 2015; 32:459-63.

8. Sevinç MM, Kınacı E, Çakar E, Bayrak S, Özakay A, Aren A, et al. Diagnostic value of basic laboratory parameters for simple and perforated acute appendicitis an analysis of 3392 cases. Ulus Travma Acil Cerrahi Derg 2016; 22:155-62.

9. Biricik S, Narcı H, Dündar GA, Ayrık C, Türkmenoğlu MÖ. Mean platelet volume and the ratio of mean platelet volume to platelet count in the diagnosis of acute appendicitis. Am J Emerg Med. 2019; 37:411-4.

10. Boshnak N, Boshnaq M, Elgohary H. Evaluation of platelet indices and red cell distribution width as new biomarkers for the diagnosis of acute appendicitis. J Invest Surg 2018; 31:121-9.

11. Ünal Y. A new and early marker in the diagnosis of acute complicated appendicitis immature granulocytes Ulusal travma ve acil cerrahi dergisi. Ulus Travma Acil Cerrahi Derg. TJTES 2018; 24:434-9.

12. Yılmaz EM, Kapçı M, Çelik S, Manoğlu B, Avcil M, Karacan E. Should alvarado and ohmann scores be real indicators for diagnosis of appendicitis and severity of inflammation. Ulus Travma Acil Cerrahi Derg 2017; 23:29-33.

13. Bilici S, Sekmenli T, Göksu M, Melek M, Avci V. Mean platelet volume in diagnosis of acute appendicitis in children. Afr Health Sci 2011;1:3.
14. Fan Z, Pan J, Zhang Y, Wang Z, Zhu M, Yang B, et al. Mean platelet volume and platelet distribution width as markers in the diagnosis of acute gangrenous appendicitis. Dis Markers. 2015; 2015.

15. Birchley D. Patients with clinical acute appendicitis should have pre-operative full blood count and C-reactive protein assays. Ann R Coll Surg Engl 2006; 88:27-32.

16. Rafiq MS, Khan MM, Khan A, Ahmad B. Total leukocyte and neutrophil count as preventive tools in reducing negative appendectomies. Ulus Travma Acil Cerrahi Derg 2015; 21: 102-6.

17. Jung SK, Rhee DY, Lee WJ, Woo SH, Seol SH, Kim DH, et al. Neutrophil-to-lymphocyte count ratio is associated with perforated appendicitis in elderly patients of emergency department. Aging Clin Exp Res 2017; 29:529-36.

18. Shimizu T, Ishizuka M, Kubota K. A lower neutrophil to lymphocyte ratio is closely associated with catarrhal appendicitis versus severe appendicitis. Surgery today 2016; 46:84-9.

19. Khan A, Riaz M, Kelly ME, Khan W, Waldron R, Barry K, et al. Prospective validation of neutrophil-to-lymphocyte ratio as a diagnostic and management adjunct in acute appendicitis. Ir J Med Sci 2018; 187:379-84.

20. Shogilev DJ, Duus N, Odom SR, Shapiro NI. Diagnosing appendicitis evidence-based review of the diagnostic approach in 2014. West J Emerg Med 2014; 15:859. 